\title{
Children's Immunology, what can we learn from animal studies (3): Impaired mucosal immunity in the gut by 2,3,7,8-tetraclorodibenzo-p-dioxin (TCDD): A possible role for allergic sensitization
}

\author{
Sho Ishikawa \\ Dept. of Molecular Preventive Medicine, Graduate School of Medicine, The Univ. of Tokyo, 7-3-1 Hongo, Bunkyo-ku, \\ Tokyo 113-0033, Japan
}

(Received February 17, 2009)

\begin{abstract}
We have recently reported breakdown of mucosal immunity in the gut by tetraclorodibenzo-p-dioxin (TCDD). That is, single oral administration of low dose 2,3,7,8-TCDD resulted in a marked decrease in IgA secretion in AhR-dependent manner and impaired oral tolerance in the gut. In the present study, we found TCDD exposure by breast feeding also resulted in decreased level of IgA in the gut. Ig production by B cells by LPS stimulation was not affected by TCDD administration. Instead, particular chemokine receptor expression on B1 cells, a major cell source for intestinal IgA antibody, was decreased in mice treated with TCDD. In consistence with this observation, B1, but not B2 cells from TCDD treated mice showed impaired chemotaxis towards B lymphocyte chemokine (BLC)/CXCL13. In contrast, chemotaxis of intestinal dendritic cells (DCs) towards secondary lymphoid-tissue chemokine (SLC)/CXCL19 was not impaired in mice treated with TCDD. Furthermore, there was no change in the number and profile of intesitinal microflora in TCDD-treated mice. These results indicate that TCDD exposure by breast feeding results in breakdown of intestinal mucosal immunity of pups and that it may be attributed in part to impaired B1 cell migration from the peritoneal cavity to intestinal mucosa.
\end{abstract}

Key words: TCDD, Mucosal immunity, IgA, Oral tolerance, Allergy

\section{INTRODUCTION}

2,3,7,8-tetraclorodibenzo-p-dioxin (TCDD) has been reported to exert a variety of adverse effects on immune responses including antibody production and cytotoxic $\mathrm{T}$ lymphocyte (CTL) generation (Hollsopple et al., 1991; Kerkvliet, 1995, 2002). Exposure to TCDD also results in decreased resistance to several infectious agents (Warren et al., 2000). However, immunological effects of dioxins on mucosal immunity in the gut have not been intensively examined so far despite that most dioxins are exposed through the digestive tract. Intestinal mucosal immunity is characterized by massive IgA secretion into the gut lumen and induction of oral tolerance against huge amounts and kinds of dietary antigens. Both intestinal IgA and oral tolerance play pivotal roles for body defense to protect against pathogens and to avoid systemic allergic sensitization by oral antigens (Strobel and Mowat, 1998; Faria and
Weiner, 1999). We previously demonstrated that mucosal immunity in the gut was impaired in BWF1 mouse strain, a murine model for systemic lupus erythematosus (SLE) (Akadegawa et al., 2005). Aged BWF1 mice developing lupus nephritis showed a defective $\operatorname{IgA}$ secretion in the gut and increased susceptibility to bacterial infection. Oral tolerance was also impaired and orally administered-antigens induced systemic allergic sensitization in the respiratory tract in these mice. On the other hand, it is well recognized that allergic diseases have been increasing for the recent several decades in developed countries and that environmental factors are more involved in disease increase than genetic factors (Schultz-Larsen, 1993). These environmental factors include increased air pollution, dust mite, dietary antigens, environmental chemicals and so on (Hopkin, 1997). We hypothesized that environmental chemicals which disrupt mucosal immunity in the gut would result in allergic sensitization by oral antigens

Correspondence: Sho Ishikawa (E-mail: yamasho@m.u-tokyo.ac.jp) 
and could be a critical environmental factor for increased allergic diseases. In fact, we found that administration of low-dose TCDD resulted in defective IgA secretion in the gut in an AhR-dependent manner and in breakdown of oral tolerance leading to antigen-specific systemic sensitization (Kinoshita et al., 2006).

In the present study, we suggest that TCDD exposure by breast feeding also results in decreased level of IgA in the gut of pups and that impaired chemotaxis of a particular B cell subset may be one of the possible mechanisms for TCDD-induced breakdown of mucosal immunity in the gut.

\section{MATERIALS AND METHODS}

\section{Mice}

Specific pathogen-free C57BL/6 mice, originally obtained from the Shizuoka Laboratory Animal Center (Shizuoka, Japan), were maintained under SPF condition in our animal facility at The University of Tokyo. 2,3,7, 8-TCDD (Daiichikagaku Co., Tokyo, Japan) in corn oil was intragastrally administrated to mothers 3 days after delivery and fecal IgA level of pups was measured every 2 weeks. In some experiments, adult C57BL/6 mice aged 6-8 weeks were used. All animal experiments complied with the standards set out in the guidelines of the University of Tokyo.

\section{Cell preparation}

Peritoneal B1 cells were purified by MACS ${ }^{\circledR}$ magnetic beads (Miltenyi Biotech, Bergisch Gladbach, Germany) from whole peritoneal cells. Briefly, T-cells, macrophages and B2 cells were depleted by incubating with a biotinylated mAb cocktail (anti-Thy1.2, anti-F4/80 plus anti-CD23 mAbs) followed by incubation with streptavidin-conjugated magnetic beads. Splenic B2 cells and $\mathrm{CD}^{+} \mathrm{T}$ cells were also isolated by MACS beads conjugated with anti-mouse B220 or anti-mouse CD4 mAb. Cell purity was more than $90 \%$ throughout the experiments.

\section{ELISA for fecal IgA}

One-hundred milligrams of fecal pellets were placed into $1.5 \mathrm{ml}$ microcentrifuge tubes, added $1 \mathrm{ml}$ (10 volumes, w/v) of phosphate buffered saline (PBS), and incubated at room temperature for $15 \mathrm{~min}$. Samples were vortexed, left to settle for $15 \mathrm{~min}$, revortexed until all material was suspended, then centrifuged at $12,000 \mathrm{rpm}$ for 10 min. The supernatant was removed and stored at $-80^{\circ} \mathrm{C}$ or immediately tested on ELISA kit for IgA (Bethyl Laboratories, Montgomery, TX, USA). Microtiter plates were coated with goat anti-mouse IgA affinity purified antibody and incubated for $60 \mathrm{~min}$. Plates were washed with PBST (PBS containing 0.05\% Tween 20) and each well was blocked with $200 \mu \mathrm{l}$ of $50 \mathrm{mM}$ Tris ( $\mathrm{pH} 8.0$ ) containing $0.15 \mathrm{M} \mathrm{NaCl}$ and $1 \%$ bovine serum albumin (BSA) for $30 \mathrm{~min}$. After washing with PBST, $100 \mu \mathrm{l}$ of test samples and standards was added per well and incubated for $60 \mathrm{~min}$. Horse radish peroxidase (HRP) labeled goat anti mouse IgA-Fc specific Ab was added to each well and incubated for $60 \mathrm{~min}$. Color was developed with HRP substrate $(3,3$ ', 5,5' -tetramethyl benzidine) for $30 \mathrm{~min}$ and read at $450 \mathrm{~nm}$ with a Emax ${ }^{\circledR}$ precision microplate reader (Molecular Devices Corporation, Sunnyvale, CA, USA).

\section{Flow cytometry}

FITC-conjugated anti-CD4 (GK1.5), anti-CD5 (537.3RRH) and anti-CD11b (M1/70); PE-conjugated antiCD8 $\alpha$ (53-6.7), anti-CD11c (HL-3), anti-B220 (RA36B2); and APC-conjugated anti-B220 (RA3-6B2) mAbs were purchased from PharMingen (San Diego, CA, USA). Lymphoid cells were stained with 1) FITC-conjugated anti-CD4, PE-conjugated anti-CD8 and APC-conjugated anti-B220 mAbs, or 2) FITC-conjugated anti-CD5 and PE-conjugated anti-B220 mAbs, or 3) FITC-conjugated anti-CD11b and PE-conjugated anti-CD11c mAbs and analyzed on Epics Elite ${ }^{\circledR}$ cell sorter (Coulter Electronics, Hialeah, FL, USA).

\section{Induction of oral tolerance}

Induction of systemic unresponsiveness to OVA (Sigma Chemical Co., St. Louis, MO, USA) was performed as described previously [7]. Briefly, mice were given $25 \mathrm{mg}$ of OVA in $250 \mu \mathrm{l}$ PBS by gastric intubation at day 0 . Control mice received PBS. At day 7 and 21 , mice were immunized and challenged subcutaneously (s.c.) with $100 \mu \mathrm{g}$ OVA in $100 \mu$ CFA (Difco Laboratories, Detroit, MI, USA). OVA-specific Ab in the serum was measured 7 days after the second s.c. immunization.

\section{OVA induced cell proliferation assay}

Twenty-five mg of OVA in $250 \mu \mathrm{l}$ PBS was administrated intragastrally three times in a week after TCDD treatment (day 0). Two weeks after the last administration, spleen and lymph nodes (axillar, pulmonary, mesenteric, renal, inguinal) were removed aseptically. Single-cell suspensions were obtained using fine-mesh screens (Cell Strainer, Becton Dickinson, Franklin Lakes, NJ, USA). 4 $\times 10^{5}$ cells were cultured in the presence of OVA or KLH $(200 \mu \mathrm{g} / \mathrm{ml})$ for 5 days at $37^{\circ} \mathrm{C}$ in $5 \% \mathrm{CO}_{2}$ in atmosphere. Each well was pulsed with ${ }^{3} \mathrm{H}$-thymidine $(1 \mu \mathrm{Ci} / \mathrm{ml})$ for the last $18 \mathrm{hr}$ of the culture. Cells were then harvested 
onto a glass filter and radioactivity was counted with a liquid scintillation counter.

\section{Chemotaxis assay}

Chemotaxis assay using ChemoTx plate (Neuro Probe, Gaithersburg, MD, USA) was performed according to manufacturer's instructions. Briefly, spleen cells were suspended at $10^{6}$ cells $/ \mathrm{ml}$ in RPMI 1640 medium containing $0.5 \%$ BSA and $20 \mathrm{mM}$ HEPES. Sixty $\mu 1$ of cell suspension was loaded on the membrane plate and placed onto a flat-bottomed microtiter plate with 96 wells containing $30 \mu \mathrm{l}$ of serially-diluted B lymphocyte chemokine (BLC) solution in each well. The plate was then incubated at $37^{\circ} \mathrm{C}$ for $90 \mathrm{~min}$ and migrated cells were collected. Cells were then stained with FITC-labeled anti-CD5 and PElabeled anti-B220 mAbs and counted on EPICS ELITE cell sorter. Chemotaxis assays for B1 and B2 cells were performed on the same plate and on the same day in each experiment because the absolute migrated cells varied in each chemotaxis assay. For chemotaxis assay for purified $\mathrm{B} 1$ and B2 cells, the mixture of $5 \times 10^{6}$ spleen and the peritoneal cells from young BWF1 mice was stained with FITC-labeled anti-CD5 and PE-labeled anti-B220 mAbs and subjected to cell sorting using EPICS ELITE cell sorter. The purity of B1 and B2 cells was more than $95 \%$ in all experiments.

\section{DNA chip analysis}

Total cellular RNA was prepared from B1 cell obtained TCDD-treated mice and DNA chip analysis performed using A24 GeneChips (Affmetrix, Santa Clara, CA, USA). Gene expression was confirmed by real-time PCR using ABI PRISM 7500 (Applied Biosystems, Foster City, CA, USA).

\section{Statistical analysis}

Statistical analysis was performed using Student's ttest. The $95 \%$ confidence limit was taken as significant.

\section{RESULTS}

\section{Decreased IgA secretion in the gut by oral administration of TCDD}

To investigate immunological effects of TCDD on intestinal mucosa, C57BL/6 mice were intragastrally administered various doses of TCDD and fecal IgA level determined by ELISA. The level of fecal IgA was dosedependently decreased in mice treated with TCDD (Fig. 1, Modified from EHPM 11:256-263, 2006). It should be noted that relatively low doses of TCDD $(0.1 \mu \mathrm{g} / \mathrm{kg}$ and

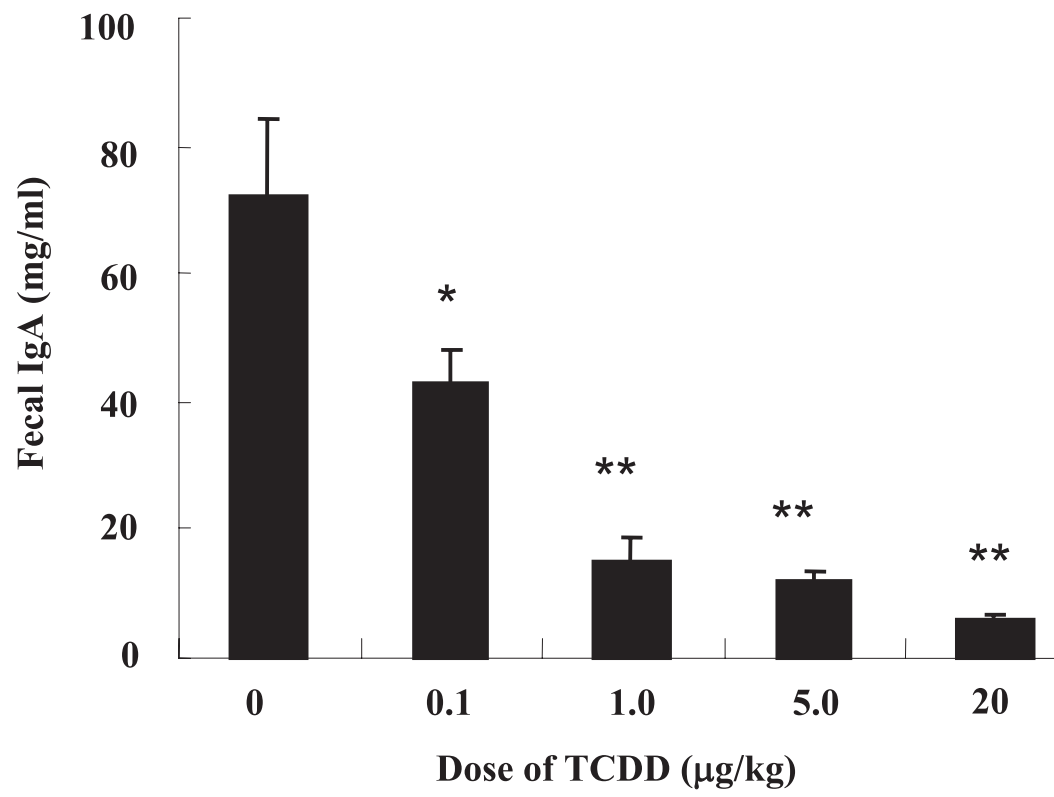

Fig. 1. TCDD suppresses IgA secretion in the gut. Dose-ependent IgA suppression by TCDD. C57BL/6 mice $(\mathrm{n}=5)$ were intragastrally administered with TCDD $(0.1,1.0,5,20 \mu \mathrm{g} / \mathrm{kg})$ and fecal IgA level was determined by ELISA 1 week after TCDD treatment. Monoclonal IgA Ab was used as control. The mean concentration \pm S.D. were presented in each graph. A representative result from four independent experiments is presented. 
$1.0 \mu \mathrm{g} / \mathrm{kg}$ ) significantly inhibit IgA secretion into the gut lumen. IgA level returned to the normal level by 4 weeks after administration of $1 \mu \mathrm{g} / \mathrm{kg}$ TCDD (data not shown). To examine whether or not the inhibitory effect of TCDD on $\operatorname{IgA}$ secretion in the gut is mediated by $\mathrm{AhR}$, a specific receptor for TCDD, fecal IgA level in AhR-deficient mice administered TCDD $(1 \mu \mathrm{g} / \mathrm{kg})$ was examined. The inhibitory effect of TCDD on IgA secretion in the gut was totally abrogated in AhR-deficient mice with C57BL/6 background while heterozygous littermates and C57BL/6 mice showed a marked decrease in IgA secretion in the gut (Fig. 2, Modified from EHPM 11:256-263, 2006). To examine the effect of TCDD exposure through breast feeding, mother mice were orally administered TCDD 3 days after delivery and fecal IgA level of pups measured by ELISA. As shown in Fig. 3 (Modified from EHPM 11:256-263, 2006), fecal IgA level was decreased in pups exposed to TCDD through breast feeding. It should be noted that the effect of TCDD on fecal IgA levels was more prominent in male than female mice.

\section{Effect of TCDD on oral tolerance}

Oral tolerance is historically and originally described as antigen-specific inhibition of antibody production by oral pre-administration of protein antigen. As shown in Fig. 4 (Modified from EHPM 11:256-263, 2006), OVAspecific IgG production was suppressed in mice which had been orally administered OVA before systemic immunization, demonstrating that oral tolerance was induced in these control mice. Oral administration of KLH did not inhibit OVA-specific IgG production (data not shown). In contrast, the suppression of IgG production was partially abrogated in TCDD treated-mice, suggesting a breakdown of oral tolerance. In consistence with the impaired oral tolerance in TCDD treated-mice, T-cells in PPs, axillar, inguinal, cervical LNs, and spleen of TCDD-treated mice were antigen-specifically sensitized and proliferated in the presence of OVA in vitro while KLH stimulation

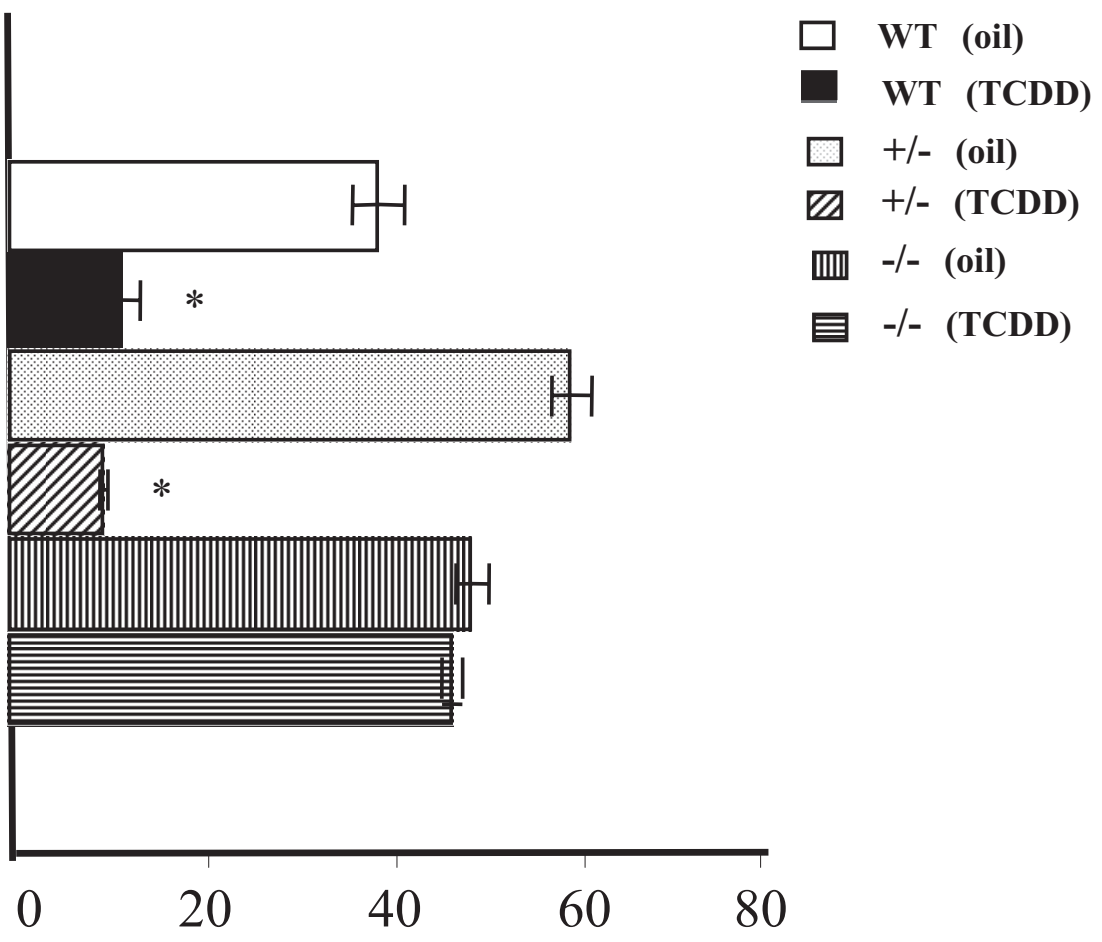

Fecal IgA (mg/ml)

Modified from Env. Health. Prev. Med. 11:256-263, 2006

Fig. 2. AhR dependent suppression of IgA secretion in TCDD-treated mice. TCDD $(1 \mu \mathrm{g} / \mathrm{kg})$ or corn oil was given to C57BL/6 (WT), AhR heterozygous (+/-), AhR deficient (-/-) mice and fecal IgA level was determined by ELSA 1 week after TCDD treatment $(\mathrm{n}=5)$. A representative result from two independent experiments is presented. Statistical analysis was performed by Student's $t$-test. * $\mathrm{p}<0.001$. 
A

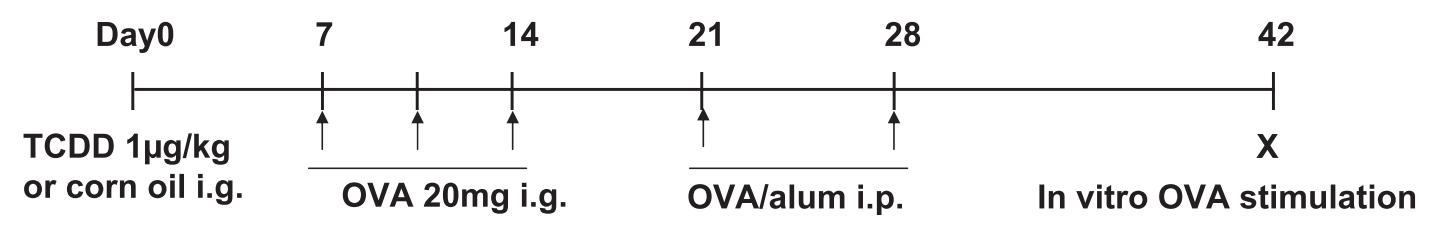

B

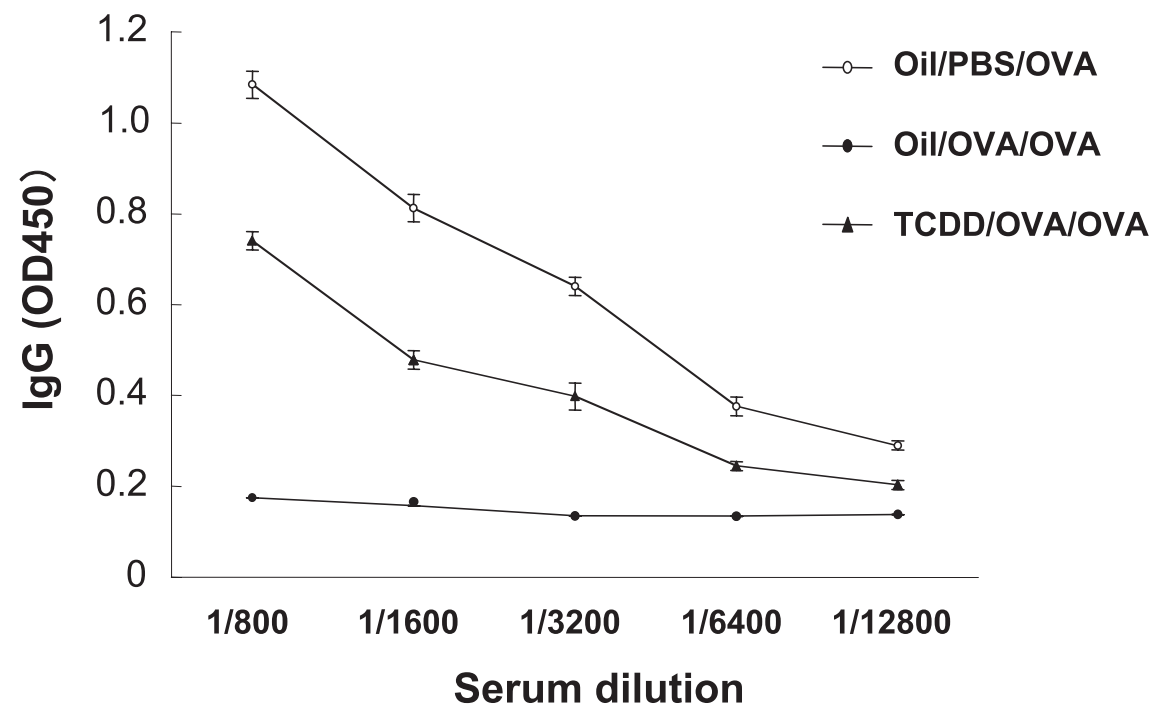

Modified From Env. Health. Prev. Med. 11:256-263, 2006

Fig. 3. Breakdown of oral tolerance and systemic sensitization by oral antigens and intact antigen uptake in TCDD-reated mice. Mice were treated with TCDD (filled square, $\mathbf{- 1}$ ) or corn oil (open triangle, $\Delta$ ) at day 0 and orally administered $25 \mathrm{mg}$ of OVA at day 7 and 14. Then mice were immunized s.c. with $100 \mu \mathrm{g}$ of OVA in CFA at day 21 and day $28(\mathrm{n}=4)$. Mice immunized with OVA plus CFA were used as positive control (open diamond, $\diamond$ ). The serum concentration of OVA specific IgG antibody at day 35 was determined by ELISA. The results are expressed as the mean \pm S.D.. A representative data from three experiments is presented. $* \mathrm{p}<0.001$.

did not induce cell proliferation (Fig. 5).

\section{Mechanisms for decreased IgA levels in TCDD-treated mice}

There was no histological change in the intestine of TCDD-treated mice and Alexa-488 labeled OVA was incorporated into the subepithelial dome of PPs normally (data not shown). Fluorescent activated cell sorter (FACS) analysis also showed no significant change in the frequency of cellular subset of immunocompetent cells in lymphoid tissues including mesenteric LNs and PPs (data not shown). In particular, frequency of $\operatorname{IgA}^{+} \mathrm{B}$-cells in the Peyer's patches and mesenteric LNs remained unchanged in TCDD-treated mice (Fig. 6A, Modified from EHPM 11:256-263, 2006). Furthermore, serum IgA level was not decreased in TCDD-treated mice (Fig. 6B, Modified from EHPM 11:256-263, 2006). Decreased level of IgA in the gut was not attributed to direct effect of TCDD on Ig production because in vitro IgM secretion by B-cells by LPS stimulation was not affected by TCDD treatment (Fig. 7). DNA chip analysis revealed that 231 genes were increased and 1,096 genes decreased in B1-cells obtained from TCDD-treated mice (Fig. 8). Real time PCR analysis confirmed that expression levels of particular chemokine receptors such as CCR2, CCR7, CXCR4 and CXCR5 were decreased in B1-cells obtained from TCDD-treated mice (Fig. 9). In consistence with this observation, chemotactic activity of B1, but not B2 cells towards BLC/ CXCL13 was impaired in TCDD-treated mice (Fig. 10). On the other hand, CD11 $\mathrm{c}^{+}$cells obtained from PPs and mesenteric LNs of TCDD-treated mice did not show impaired chemotaxis towards secondary lymphoid-tissue chemokine (SLC)/CCL21 (Fig. 11). Furthermore, the number and frequency of major commensal bacterial species which were believed to play a role in the maintenance of oral tolerance were not changed in TCDD-treated mice (Fig. 12). 

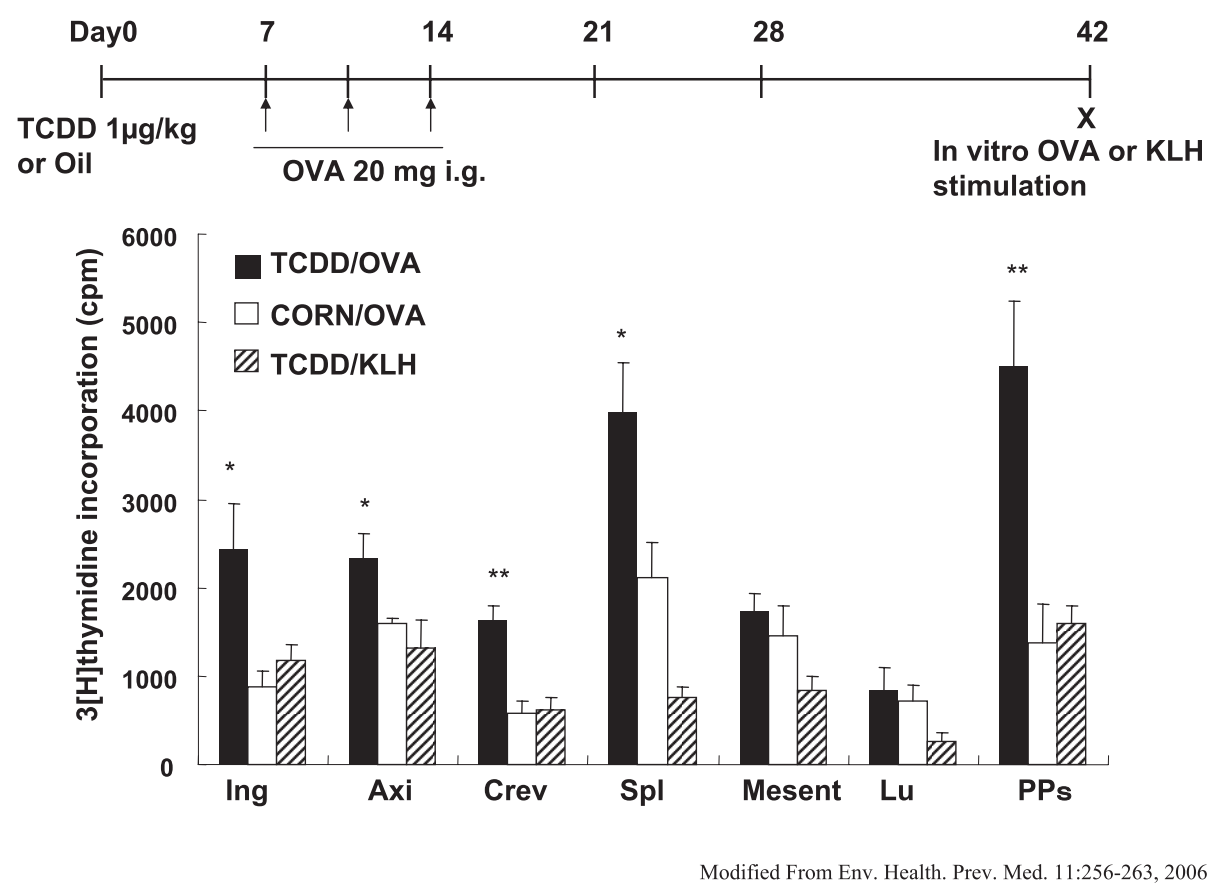

Fig. 4. Systemic sensitization with orally administered OVA by TCDD pretreatment. Mice were treated with TCDD on day 0 and then mice were intragastrally given $25 \mathrm{mg}$ of OVA twice at day 7, 10 and 14. At day 28, single cell suspensions were obtained from spleen (Spl), inguinal (Ing), axillar (Axil), mesenteric (Mes), pulmonary (Pulm) lymph nodes, and Peyer's patches (PPs) and stimulated in vitro with OVA or KLH $(200 \mu \mathrm{g} / \mathrm{ml})$ at $37^{\circ} \mathrm{C}$ for 5 days. Cell proliferation was measured by ${ }^{3} \mathrm{H}$-thymidine incorporation as described in Material and Methods. Results are presented as the means \pm S.D. $(n=4)$. A representative data from three experiments is presented. ${ }^{*} \mathrm{p}<0.05, * * \mathrm{p}<0.01$.

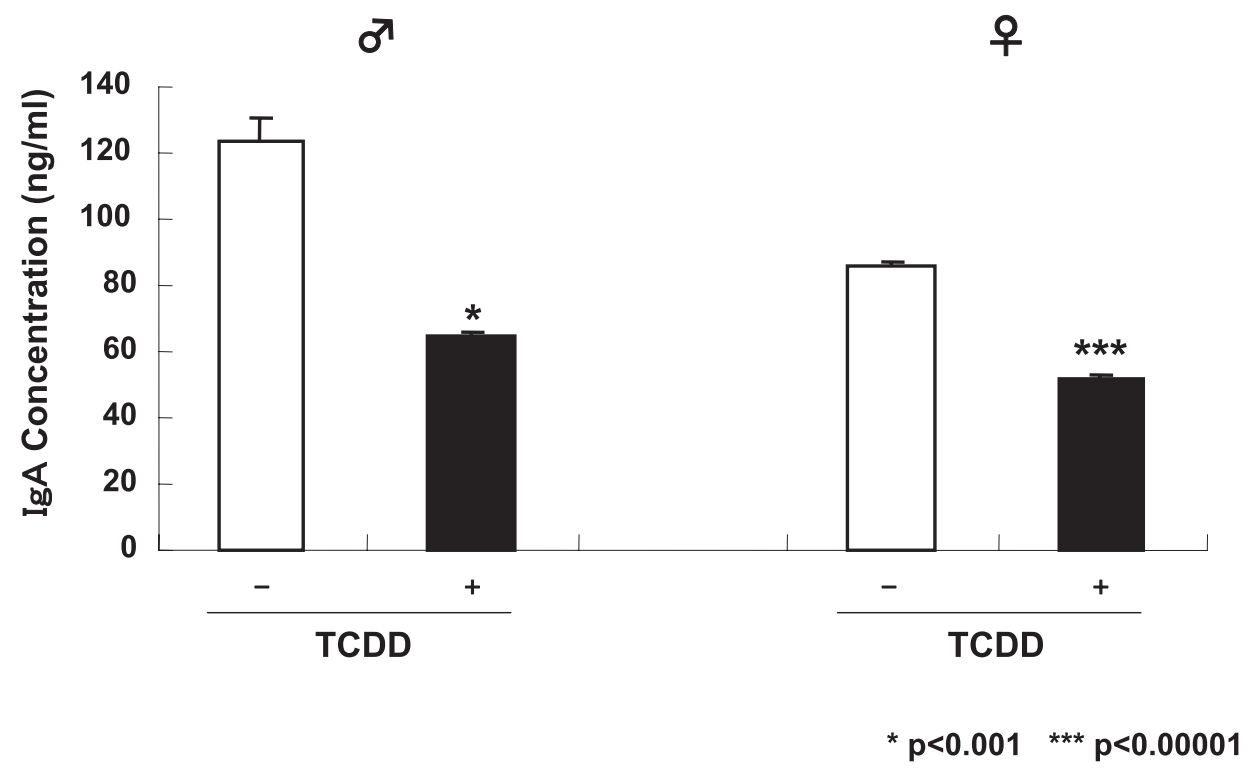

Fig. 5. Effect of TCDD exposure through mother milk on fecal IgA level of pups. TCDD was administered to mother 3 days after birth and fecal IgA levels of pups measured by ELISA 4 weeks after delivery $(n=5$ or 6$)$. 


\section{A}

\section{$\lg \mathrm{A}+$ cells}

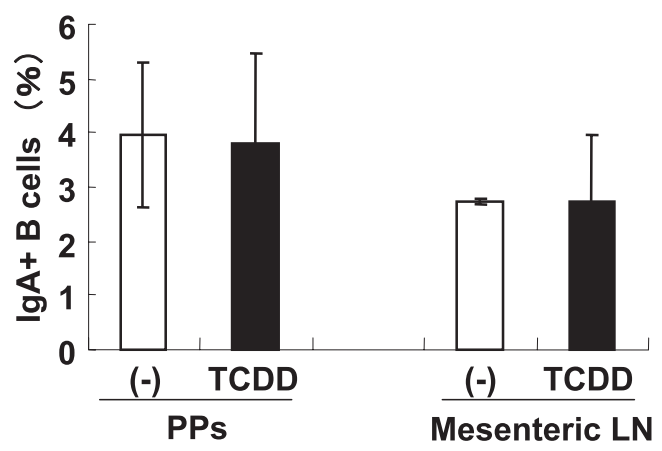

B

\section{Serum $\lg A$}
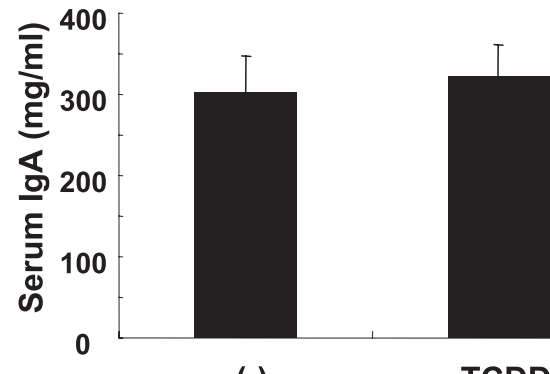

$(-)$

TCDD

Modified From Env. Health. Prev. Med. 11:256-263, 2006

Fig. 6. No change in the frequency of $\operatorname{IgA}^{+}$cells and serum level of IgA in TCDD-treated mice. A. Cells prepared from PPs or mesenteric LNs were stained with FITC-anti-IgA, PE-anti-B220, and APC-anti-CD19 Abs. The percentages of IgA+B220 ${ }^{+}$ cells in CD19+ cells were presented $(n=3)$. B. Serum concentration of IgA in TCDD-treated and control mice $(n=3)$ was measured by ELISA as described in Materials and Methods.

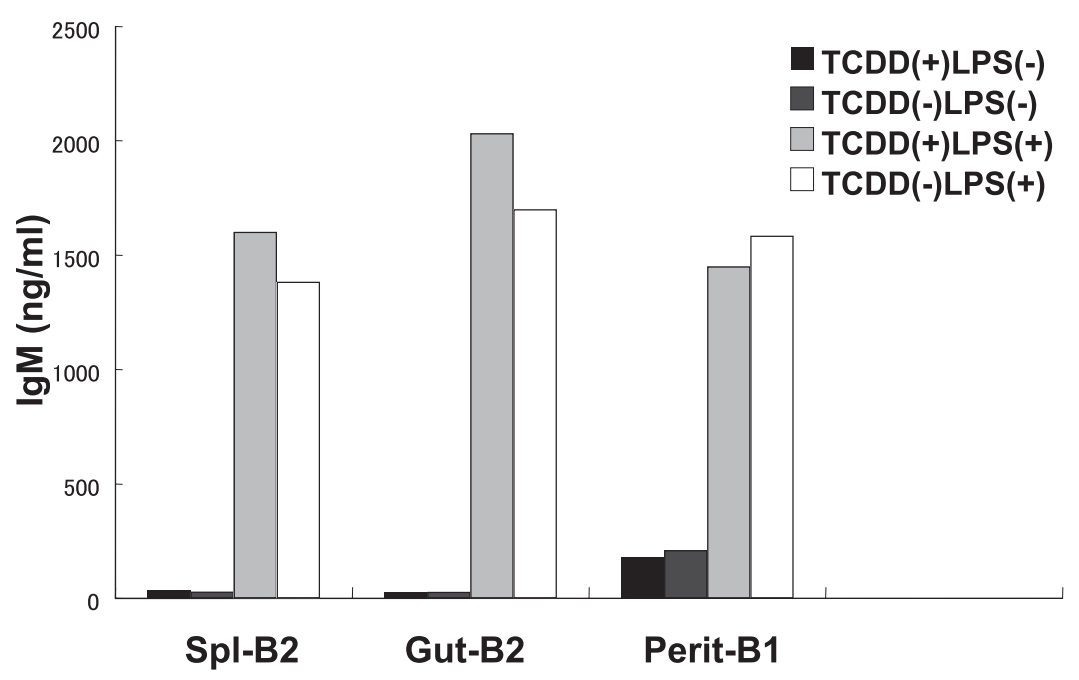

Fig. 7. Unimpaired IgM production by B1 and B2 cells on stimulation with LPS. B1 and B2 cells from TCDD-treated or control mice were stimulated in vitro in the presence of LPS $(5 \mathrm{mg} / \mathrm{ml})$ and IgM concentration in the culture supernatant was measured 5 days after stimulation. 


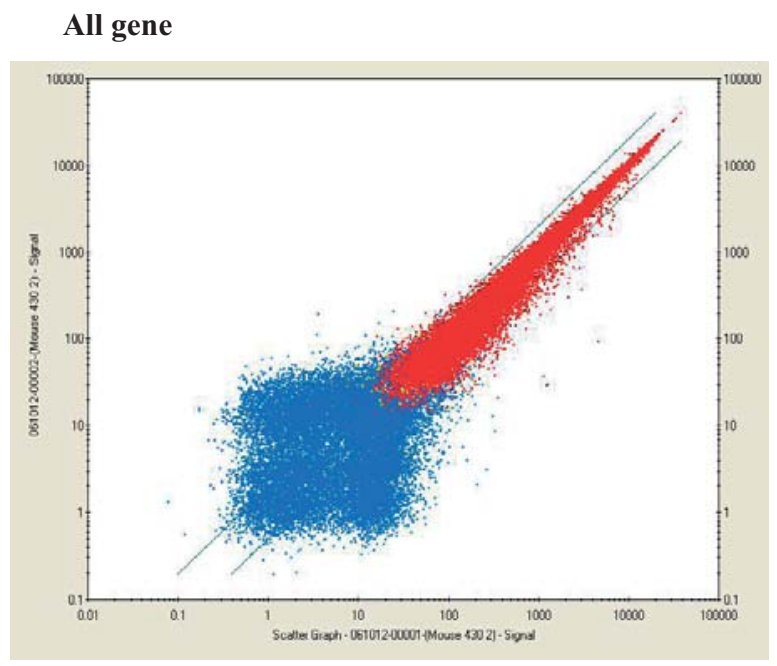

\section{Present gene}

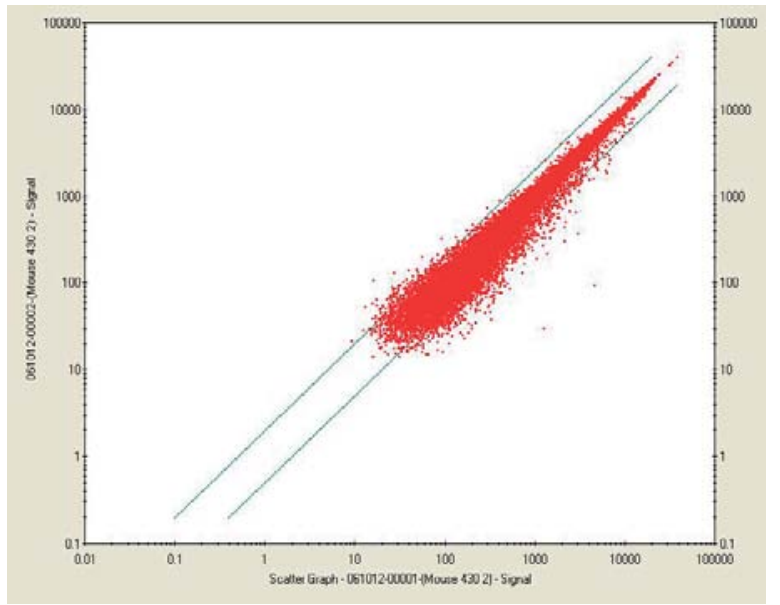

Fig. 8. DNA chip analysis on TCDD-treated B1 cells. Total cellular RNA was prepared from B1 cells obtained from TCDD-treated mice 1 week after injection and subjected to DNA chip analysis as described in Materials and Methods. Significant expression levelsof genes are dotted as present genes.

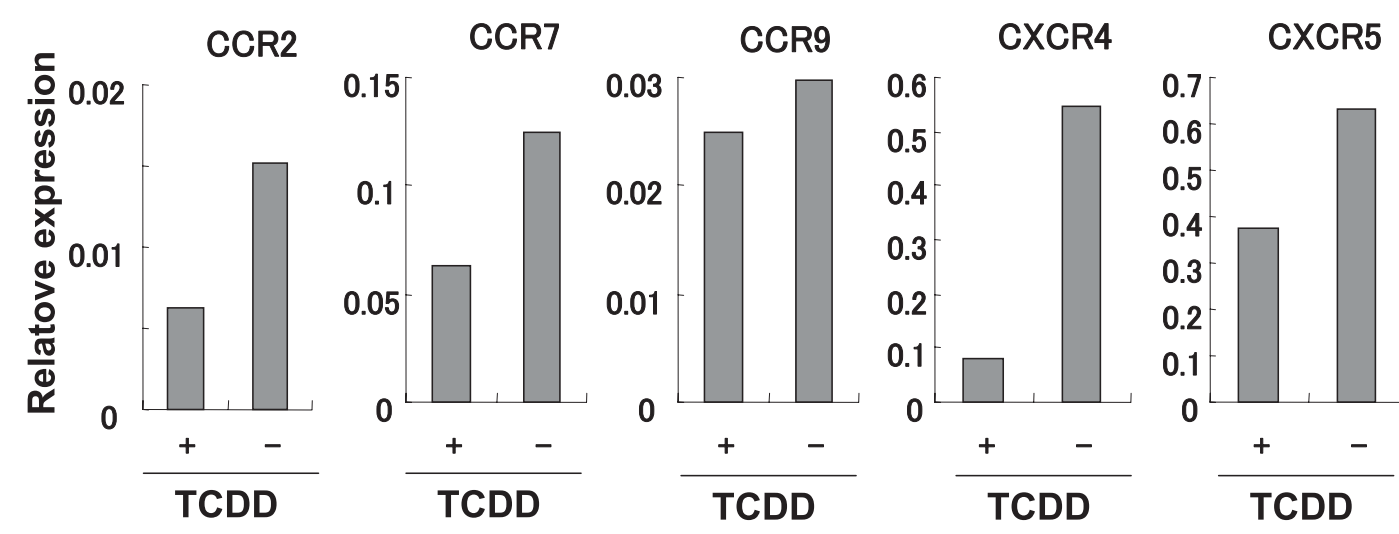

Fig. 9. Decreased expression of chemokine receptors in B1-cells in TCDD-treated mice. Total cellular RNA was prepared from sorted B1 cells from TCDD-treated or control mice and expression levels of chemokine receptors were measured by realtime PCR.

\section{DISCUSSION}

We previously reported breakdown of mucosal immunity in the gut by a single oral administration of 2,3,7,8TCDD (Kinoshita et al., 2006). That is, relatively low-dose TCDD administration resulted in a marked decrease in IgA level in the gut in an AhR-dependent manner and impaired oral tolerance in the gut. The mechanism for decreased IgA level in the gut, however, remained to be elucidated. There was no histological change in the intestine in TCDDtreated mice. Cellular subsets of immunocompetent cells in lymphoid tissues including PPs, spleen, thymus and peripheral LNs also remained unchanged. The frequency of $\mathrm{IgA}^{+} \mathrm{B}$-cells was not decreased in the mesenteric LNs and PPs in TCDD-treated mice in FACS analysis whereas those in the intestinal lamina propria were decreased in immunofluorescent study in TCDD-treated mice. In the present study, we found that expression levels of par- 
Impaired mucosal immunity in the gut by TCDD

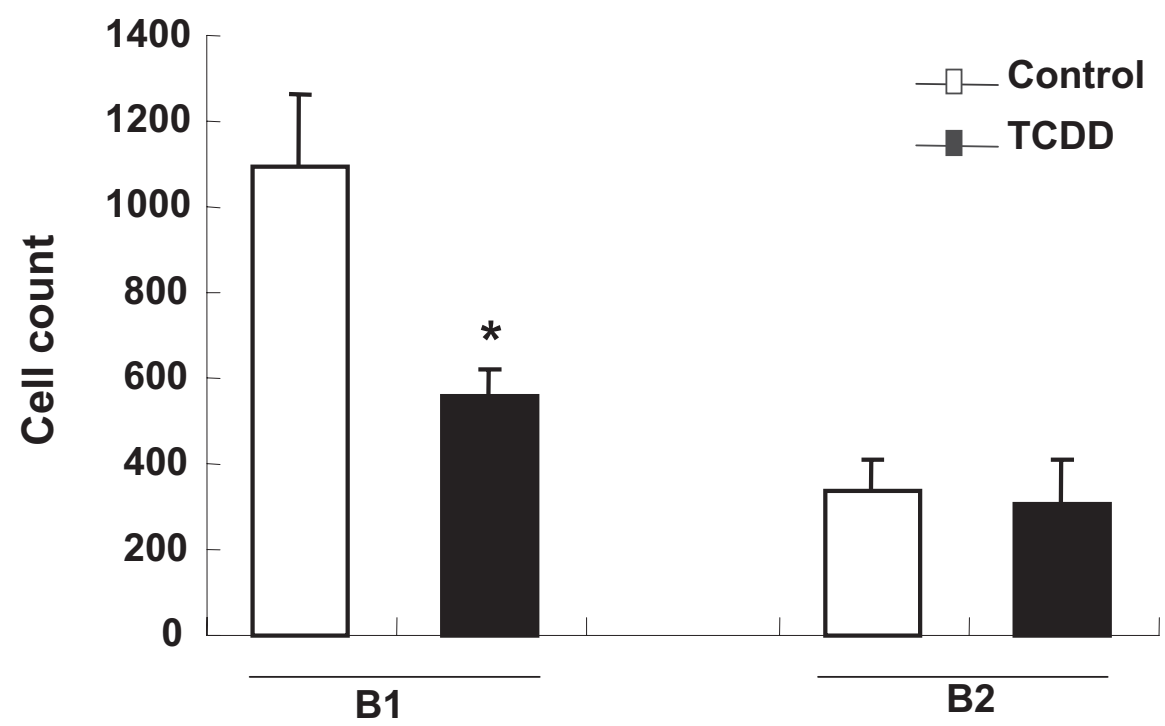

Fig. 10. Impaired chemotaxis of $B 1$, but not $B 2$ cells TCDD-treated mice. $B 1$ and $B 2$ cells enriched by MACS ${ }^{\circledR}$ beads were subjected to chemotaxis assay on BLC/cXCL13 as described in Materials and Methods. ${ }^{*} \mathrm{p}<0.001$.

40

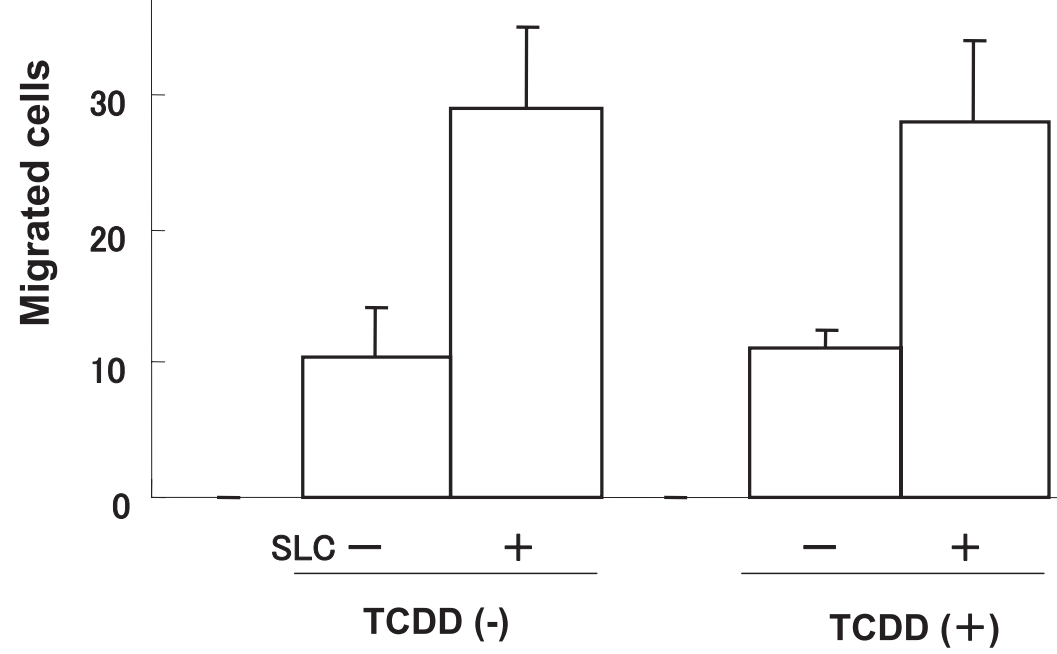

Fig. 11. Chemotaxis assay on dendritic cells (DCs). CD11 $\mathrm{c}^{+}$cells obtained from mesenteric LNs and PPs of TCDD-treated or control mice by MACS ${ }^{\circledR}$ beads were subjected to chemotaxis assay on SLC/CCL21 as in Fig. 9.

ticular chemokine receptors were decreased in B1-cells, a unique B-cell subset which is distinguished from conventional B-cells (B2 cells) by their origin, cell surface phenotype and unique tissue distribution, capacity for self-renewal (Hardy and Hayakawa, 1986). B1-cells have been considered to be involved in autoantibody produc- tion in the development of particular autoimmune diseases. It is also reported that approximately half of $\mathrm{IgA}^{+}$cells in the intestinal lamina propria are derived from B1-cells and that they play a pivotal role for innate mucosal immunity in the gut although the site for IgA class-switching and differentiation to IgA-secreting plasma cells remains 


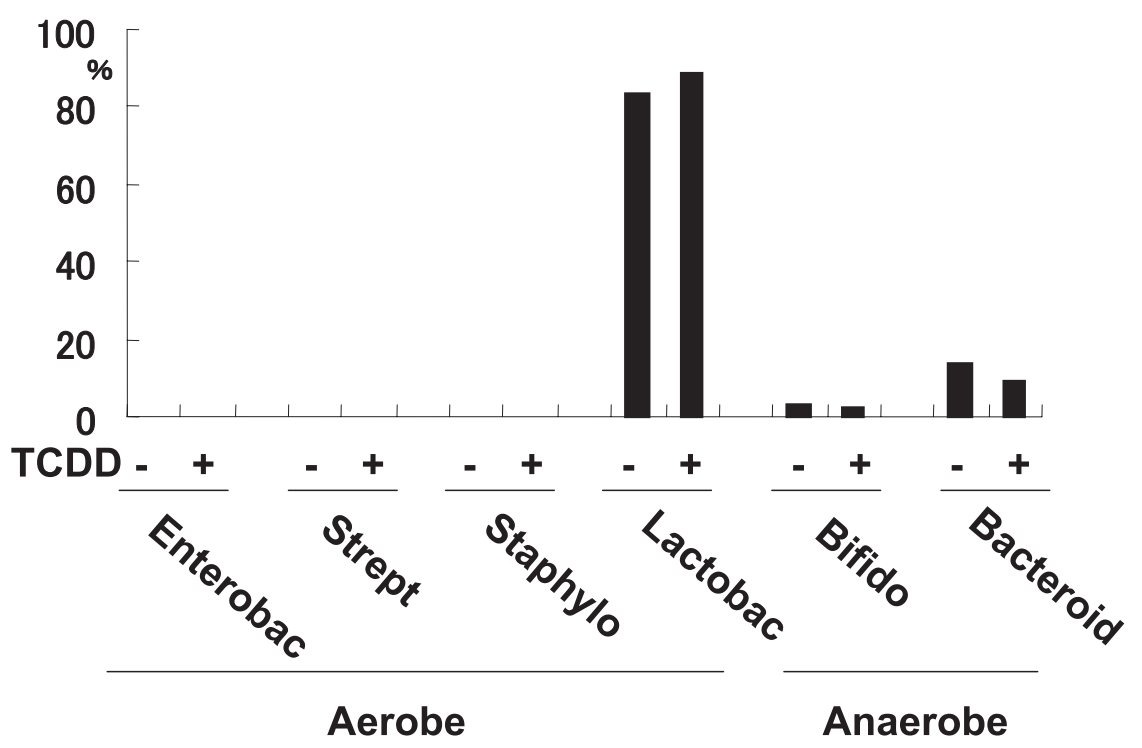

Fig. 12. Effect of TCDD on the number and frequency of commensal microflora in the intestine. Fecal samples were collected one week after TCDD administration and the number and frequency of aerobes (Lactobacillus, Enterococcus, Streptococcus, Staphylococcus) and anaerobes (Bacteroides and Bifidobacterium) were determined after appropriate culture at Intestinal flora laboratory of Calpis Co., Ltd..

to be elucidated (Kroese et al., 1989; Beagley et al., 1995; Murakami and Honjo, 1995; Macpherson et al., 2000). It has been recently demonstrated that constitutively active aryl hydrocarbon receptor causes selective loss of peritoneal B1a $\left(\mathrm{CD} 5^{+} \mathrm{B} 220^{\text {low }} \mathrm{IgM}^{\text {high }}\right)$ cells (Anderson et al., 2003), suggesting that the B1-cell is a sensitive cellular target for TCDD. On the other hand, ex vivo IgM secretion by B1-cells on LPS simulation was not affected by TCDD treatment as shown in the present study, suggesting that decreased level of IgA in the gut was not attributed to direct effect of TCDD on Ig production. Instead, we favor the idea that impaired B1-cell trafficking by TCDD from the peritoneal cavity to the intestinal mucosa could be one of the causes for decreased level of IgA in the gut (Fig. 13).

Another important finding in the present study is that TCDD exposure by breast feeding also results in decreased level of intestinal IgA in the pups. Maternal depots of TCDD, stored primarily in adipose tissue, are efficiently transferred to pups during nursing period. Maternal TCDD levels rapidly decreased during lactation period while tissue levels in the nursing pups increased. Tissue levels in the offspring even exceed those of their mothers during the 3-week period after birth. Thus, lactation serves as a significant route of exposure for the developing neonate (Nau et al., 1986). It is previous- ly reported that lactational exposure to TCDD induced hydronephrosis both in mice and rats (Couture-Haws et al., 1991; Nishimura et al., 2006). Since development of mucosal immune system does not cease at birth as well as renal development, it is not surprising that TCDD exposure by breast milk decreases IgA levels in the gut at relatively low dose. Furthermore, immature mucosal immune system of newborn infants may be much more sensitive to TCDD exposure. Therefore, our findings would have a significant impact on the risk assessment of TCDD for neonates and infants given that babies with breast-feeding take 15-20 times more TCDD than the dose of tolerable daily intake (TDI). Decreased level of IgA in the gut would result in increased frequency of infection and altered distribution of commensal bacterial microflora which plays a role for oral tolerance.

Breakdown of oral tolerance by TCDD is another interesting finding in the present study. Oral tolerance is historically and originally described as antigen-specific inhibition of systemic IgG antibody production by oral pre-administration of protein antigen (Strobel and Mowat, 1998; Faria and Weiner, 1999). Many studies have been performed using a similar experimental protocol to that used in the present study to demonstrate the presence or absence of oral tolerance. However, the precise mechanism for oral tolerance still remains controversial 


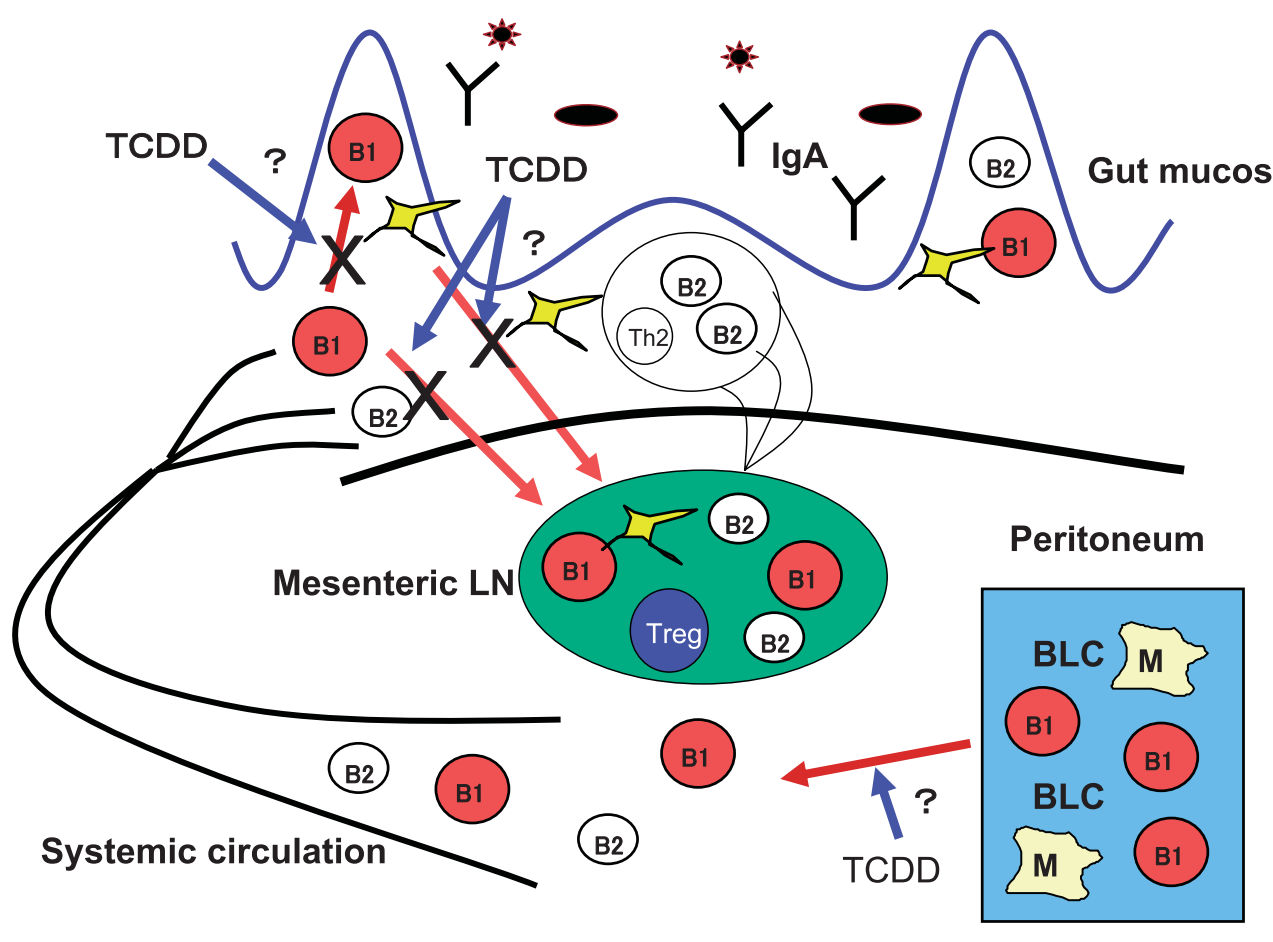

Fig. 13. Hypothetical model for TCDD-induced breakdown of mucosal immunity. TCDD treatment possibly impaires B1-cell trafficking from the peritoneal cavity to the lamina propria in gut. This results in decreased level of IgA in the gut lumen without directly affecting Ig secretion.

(Mowat, 2003). It was previously reported that regulatory T-cells producing TGF- $\beta$ and/or IL-10 were induced in PPs upon oral administration of protein antigens (Santos et al., 1994; Tsuji et al., 2001). However, the classical idea for the pivotal role of PPs in oral tolerance has been challenged by several studies demonstrating that oral tolerance could be induced independently of PPs (Spahn et al., 2001). It was also demonstrated that the spleen plays an important role for oral tolerance (Suh et al., 1993). These results favor the idea that mesenteric LNs and/or spleen are critical lymphoid organs as the induction site for oral tolerance although they do not exclude a physiological role of PPs. Accumulating evidence also suggests that DCs in the gut play a pivotal role for oral tolerance (Viney et al., 1998, Huang et al., 2000; Chirdo et al., 2000, Sun et al., 2007). However, the frequency of CD11 $\mathrm{c}^{+}$cells remained unchanged in PPs, mesenteric LNs and spleen before and after TCDD treatment. Functional analysis on DCs with different localization is under investigation to elucidate the mechanism involved in disrupted oral tolerance by TCDD. It has been recently demonstrated that TCDD generates CD25+CD4 T cells with regulatory function in a GVH model (Funatake et al., 2005). However, FACS analysis showed only a marginal change in the frequency of $\mathrm{CD} 25^{+} \mathrm{CD} 4 \mathrm{~T}$ cells in the PPs, mesenteric LNs, and spleen $(6.3 \pm 0.28,12.3 \pm$ $0.28,8.95 \pm 0.21$ in TCDD-treated mice and $4.25 \pm 0.35$, $11.4 \pm 0.21,7.6 \pm 0.28$ in control mice, respectively). Effect of TCDD on Treg trafficking remains to be examined. Although commensal bacterial microflora plays a role in the development of oral tolerance (Sudo et al., 1997), there was no change in the number and frequency of major bacterial species.

As a result of breakdown of oral tolerance, T-cells in PPs, axillar inguinal and cervical LNs were sensitized by orally administered OVA. It is known that patients with atopic dermatitis show high frequency of food allergy and that dietary allergens such as egg albumin often turn out to be the allergen in the skin in these patients, indicating the existence of immunological cross talk between the intestinal mucosa and the skin. It is considered that microbial infection, excessive antibiotic administration, early onset of a weaning diet and so on are the causes for systemic allergic sensitization to oral antigens in infants. 
Our findings suggest that TCDD can be a possible candidate for such disruptors for mucosal immunity leading to allergic sensitization.

Collectively, we have demonstrated that relatively low dose of TCDD results in breakdown of intestinal mucosal immunity and systemic sensitization by oral antigen in mice. Disrupted chemotaxis of B1 cells may be one of the mechanisms for defective IgA in the gut in TCDD-treated mice. Thus, immunological effects of environmental chemicals such as dioxins should be assessed on the basis of mucosal immunity in the gut. This may also provide a new insight for understanding environmental factors responsible for increased allergic diseases in recent decades.

\section{ACKNOWLEDGMENTS}

We thank Dr. C. Tohyama (Univ. of Tokyo) and Dr. R.E. Peterson (Univ. of Wisconsin) for kind gift of AhR deficient mice and Ms. Y. Kurotaki and Y. Mochimaru for excellent technical assistance. This work was supported by grants from SORST (Solution Oriented Research for Science and Technology, Japan Science and Technology Corporation), LRI (The Long-ranged Research Initiative) by Japan Chemical Industry Association, and The Japan Health Sciences Foundation.

This peer-reviewed article is based upon a lecture presented at the 35th Annual Meeting of Japanese Society of Toxicology, June 2008 in Tokyo under the theme of "Children's Toxicology", June 2008 in Tokyo.

\section{REFERENCES}

Akadegawa, K., Ishikawa, S., Sato, T., Suzuki, J., Yurino, H., Kitabatake, M., Ito, T., Kuriyama, T. and Matsushima, K. (2005): Breakdown of mucosal immunity in the gut and resultant systemic sensitization by oral antigens in a murine model for systemic lupus erythematosus. J. Immunol., 174, 5499-5506.

Anderson, P., Ridderstad, A., Mcguire, J., Petterson, S., Poellinger, L. and Hanberg, A. (2003): A constitutively active aryl hydrocarbon receptor causes loss of peritoneal B1 cells. Biochem. Biophys. Res. Comm., 302, 336-341.

Beagley, K.W., Murray, A.M., McGhee, J.R. and Eldridge, J.H. (1995): Peritoneal cavity CD5 (B1a) B cells: Cytokine induced IgA secretion and homing to intestinal lamina propria in SCID mice. Immunol. Cell Biol., 73, 425-432.

Chirdo, F.G., Millington, O.R., Beacock-Sharp, H. and Mowat, A.M. (2000): Immunomodulatory dendritic cells in intestinal lamina propria. Eur J Immunol., 35, 1831-1840.

Couture-Haws, L., Harris, M.W., Lockhart, A.C. and Birnbaum, L.S. (1991): Evaluation of the persistence of hydronephrosis induced in mice following in utero and/or lactational exposure to $2,3,7,8$ tetrachlorodibenzo-p-dioxin. Toxicol. Appl. Pharmacol., 107, 402412 .
Faria, A.M. and Weiner, H.L. (1999): Oral tolerance: mechanisms and therapeutic applications. Adv. Immunol., 73, 153-264.

Funatake, C.J., Marshal, N.B., Stephan, L.B., Mourich, D.V. and Kerkvliet, N.I. (2005): Activation of the aryl hydrocarbon receptor by 2,3,7,8-tetrachlorodibenzo-p-dioxin generates a population of $\mathrm{CD} 4{ }^{+} \mathrm{CD} 25^{+}$cells with characteristics of regulatory $\mathrm{T}$ cells. J. Immunol., 175, 4184-4188.

Hardy, R.R. and Hayakawa, K. (1986): Development and physiology of Ly-1 B and its human homolog, Leu-1 B. Immunol. Rev., 93, 53-79.

Hollsopple, M.P., Snyder, N.K., Wood, S.C. and Morris, D.L. (1991): A review of 2,3,7,8-tetraclorodibenzo-p-dioxin-induced changes in immuno-competence. Update Toxicol., 69, 219-255.

Hopkin, J.M. (1997): Mechanisms of enhanced prevalence of asthma and atopy in developed countries. Curr. Opin. Immunol., 9, 788-792.

Huang, F.P., Platt, N., Wykes, M., Major, J.R., Powell, T.J., Jenkins, C.D. and MacPherson, G.G. (2000): A discrete subpopulation of dendritic cells transports apoptotic intestinal epithelial cells to T cell areas of mesenteric lymph nodes. J. Exp. Med., 191, 435444.

Kerkvliet, N.I. (1995): Immunological effects of chlorinated dibenzo-p-dioxins. Eniviron. Health Perspect., 103, 47-53.

Kerkvliet, N.I. (2002): Recent advances in understanding the mechanisms of TCDD immunotoxicity. Int. Immunopharamacol., $\mathbf{2}$, 277-291.

Kinoshita, H., Abe, J., Akadegawa, K., Yurino, H., Uchida, T., Ikeda, S., Matsushima, K. and Ishikawa, S. (2006): Breakdown of mucosal immunity in gut by 2,3,7,8-tetrachlorodibenzo-pdioxin (TCDD). Env. Health Prev. Med., 11, 256-263.

Kroese, F.G., Butcher, E.C., Stall, A.M., Lalor, P.A., Adams, S. and Herzenberg, L.A. (1989): Many of the IgA producing plasma cells in murine gut are derived from self-replenishing precursors in the peritoneal cavity. Int Immunol., 1, 75-84.

Macpherson, A.J., Gatto, D., Sainsbury, E., Harriman, G.R., Hengartner, H. and Zinkernagel, R.M. (2000): A primitive T cell-independent mechanism of intestinal mucosal IgA responses to commensal bacteria. Science, 288, 2222-2226.

Mowat, A.M. (2003): Anatomical basis of tolerance and immunity to intestinal antigens. Nat. Rev. Immunol., 3, 331-341.

Murakami, M. and Honjo, T. (1995): Involvement of B-1 cells in mucosal immunity and autoimmunity. Immunol. Today, 16, 534539.

Nau, H., Bass, R. and Neubert, D. (1986): Transfer of 2,3,7,8-tetrachlorodibenzo-p-dioxin (TCDD) via placenta and milk, and postnatal toxicity in the mouse. Arch. Toxicol., 59, 36-40.

Nishimura, N., Yonemoto, J., Nishimura, H. and Tohyama, C. (2006): Localization of cytochrome P450 1A1 in a specific region of hydronephrotic kidney of rat neonates lactationally exposed to 2,3,7,8-tetrachlorodibenzo-p-dioxin. Toxicol., 227, 117-126.

Nohara, K., Izumi, H., Tamura, S., Nagata, R. and Tohyama, C. (2002). Effect of low-dose 2,3,7,8-tetrachlorodibenzo-p-dioxin (TCDD) on influenza A virus-induced mortality in mice. Toxicology, 170, 131-138.

Santos, L.M., al-Sabbagh, A., Londono, A. and Weiner, H.L. (1994): Oral tolerance to myelin basic protein induces TGF- $\beta$ secreting regulatory T cells in Peyer's patches of SJL mice. Cell Immunol, 157, 439-447.

Schultz-Larsen, F. (1993): The epidemiology of atopic dermatitis. Monogr. Allergy, 31, 9-328.

Spahn, T.W., Fontana, A., Faria, A.M., Slavin, A.J., Eugster, H.P., 
Impaired mucosal immunity in the gut by TCDD

Zhang, X., Coni, P.A., Ruddle, N.H., Flavel, R.A., Rennert, P.D. and Weiner, H.L. (2001): Induction of oral tolerance to cellular immune responses in the absence of Peyer's patches. Eur. J. Immunol., 31, 1278-1287.

Strobel, S. and Mowat, A.M. (1998): Immune responses to dietary antigens: oral tolerance. Immunol. Today, 19, 173-181.

Sudo, N., Sawamura, S., Tanaka, K., Aiba, Y., Kubo, C. and Koga, Y. (1997): The requirement of intestinal bacterial flora for the development of an IgE production system fully susceptible to oral tolerance induction. J. Immunol., 159, 1739-1745.

Suh, E.D.W., Vistica, B.P., Chi-Chao, C., Raber, J.M., Gery, I. and Nussenblatt, R.B. (1993): Splenectomy abrogates the induction of oral tolerance in experimental autoimmune uveoretinitis. Curr. Eye Res., 12, 833-839.

Sun, C.M., Hall, J.A., Blank, R.B., Bouladoux, N., Oukka, M.,
Mora, J.R. and Belkaid, Y. (2007): Small intestine lamina propria dendritic cells promote de novo generation of Foxp3 Treg cells via retinoic acid. J. Exp. Med., 204, 1775-1785.

Tsuji, N.M., Mizumachi, K. and Kurisaki, K. (2001): Interleukin10 -secreting Peyer's patches are responsible for active suppression in low-dose oral tolerance. Immunology, 103, 458-464.

Viney, J.L., Mowat, A.M., O’Malley, J.M., Williamson, E. and Fanger, N.A. (1998): Expanding dendritic cells in vivo enhances the induction of oral tolerance. J. Immunol., 160, 5815-5825.

Warren, T.K., Mitchell, K.A. and Lawrence, B.P. (2000): Exposure to 2,3,7,8-tetrachlorodibenzo-p-dioxin (TCDD) suppresses the humoral and cell-mediated immune responses to influenza A virus without affecting cytolytic activity in the lung. Toxicol. Sci., 56, 114-123. 
